\title{
Expresión de enzimas relacionadas con el metabolismo de glucocorticoides en tejidos ováricos bovinos
}

\author{
Expression of enzymes related with the metabolism of the \\ glucocorticoids in bovine ovarian tissue
}

\author{
Michael López C, ${ }^{1 *}$ MVZ, Ayelen Amweg, ${ }^{2}$ Lic. en Biotec, Matías Stangaferro, ${ }^{2}$ MV, \\ Hugo Ortega, ${ }^{2}$ Ph.D.
}

\begin{abstract}
${ }^{1}$ Universidad Pedagógica y Tecnológica de Colombia, Facultad de Ciencias Agropecuarias, Escuela de Medicina Veterinaria y Zootecnia, Tunja, Colombia. ${ }^{2}$ Universidad Nacional del Litoral, Facultad de Ciencias Veterinarias, Centro de Experimentaciones Biológicas y Bioterio, Laboratorio de Biología Celular y Molecular, Esperanza - Santa Fe, Argentina. *Correspondencia: agame_el_coraire@hotmail. com
\end{abstract}

Recibido: Marzo de 2011; Aceptado: Febrero de 2012.

\section{RESUMEN}

Objetivo. Identificar la expresión de enzimas relacionadas con el metabolismo de glucocorticoides en tejidos ováricos bovinos. Materiales y métodos. Se obtuvieron muestras de tejidos provenientes de ovarios sanos $(n=10)$ y con Enfermedad Quística Ovárica (COD) $(n=10)$, a las cuales luego de su procesamiento histológico, se las incluyó en parafina. Mediante la técnica de inmunohistoquímica indirecta, se identificaron in situ en folículos primarios, secundarios, terciarios, atrésicos y quistes de las isoformas 1 y 2 de la enzima 11ß-hidroxiesteroide deshidrogenasa (11ßHSD) utilizando anticuerpos específicos. Resultados. La expresión de la enzima $11 \beta \mathrm{HSD}-1$ presentó diferencias significativas únicamente en las células de la granulosa de los diferentes grupos foliculares. La enzima 11ßHSD-2 mostró diferencias significativas con respecto a su expresión en las células de la granulosa de los folículos primarios comparada con los folículos secundarios y quísticos. En las células de la teca interna, esta diferencia se observó entre los folículos terciarios y los folículos atrésicos y quísticos. En las células de la teca externa, los folículos terciarios mostraron diferencias significativas en su expresión con respecto a los folículos atrésicos. Conclusiones. Se demostró la presencia de las isoformas tipo I y II de $11 \beta \mathrm{HSD}$ en tejidos ováricos bovinos obtenidos de frigorífico, lo que permite inferir la existencia de un mecanismo endocrino de regulación de la actividad de los glucocorticoides, que podría alterar el patrón normal de desarrollo folicular generando estructuras foliculares anovulatorias y/o quistes foliculares, y al mismo tiempo anestro y otras alteraciones reproductivas en bovinos.

Palabras clave: Bovinos, cortisol, Estrés, inmunohistoquímica, quistes foliculares (Fuente:CAB). 


\section{ABSTRACT}

Objective. Identify the expression of enzymes related to metabolism of glucocorticoids in bovine ovarian tissue. Materials and methods. Samples of tissues of healthy ovaries $(n=10)$ and ovaries with Cystic Ovarian Disease (COD) $(n=10)$ were obtained and then preserved in paraffin after their histological processing. By applying the indirect inmunohistochemistry technique and using specific antibodies it was possible to identify in situ the 1 and 2 isoforms of the $11 \beta$-hidroxiesteroide dehydrogenase (11ßHSD) enzyme in primary, secondary, tertiary, atretic and cystic follicles. Results. The expression of the $11 \beta \mathrm{HSD}-1$ enzyme showed significant differences only in the granulosa cells of the different follicular groups. The $11 \beta$ HSD-2 enzyme showed significant differences with respect to its expression in the granulosa cells of primary follicles compared to the secondary and cystic follicles. In the cells of the theca interna this difference was observed between the tertiary and the atretic and cystic follicles. In the external theca cells, the tertiary follicles showed significant differences in its expression with respect to the atretic follicles. Conclusions. The presence of isoforms I type and II type of $11 \beta \mathrm{HSD}$ was observed in ovarian bovine tissues, obtained in slaughterhouses. This allows for concluding the existence of an endocrine mechanism, which regulates glucocorticoid activity. This mechanism allows for the alteration of the normal level of follicular development by generating follicular anovulatory structures and/or follicular cysts and at the same time generating anestrus and others reproductive alterations in cattle.

Key words: Cattle, cortisol, follicular cyst, inmunohistochemistry, stress (Source:CAB).

\section{INTRODUCCIÓN}

Los glucocorticoides son hormonas esteroides, de la categoría de adrenocorticales, de la cual también son parte los mineralocorticoides, estos son capaces de atravesar la membrana plasmática e interaccionar en el citoplasma con receptores citoplasmáticos específicos. Por otra parte, los glucocorticoides tienen importantes efectos clínicos, a través de la inhibición de la respuesta inflamatoria, que consiste en la prevención de la dilatación capilar, la extravasación del líquido a los espacios tisulares, la migración leucocitaria, el depósito de fibrina y la síntesis de tejido conjuntivo. Una de las vías por las que estas hormonas inhiben la respuesta inflamatoria es mediante la supresión de la formación de sustancias que promueven la inflamación, como prostaglandinas, tromboxanos y leucotrienos (1). Los glucocorticoides actúan directamente sobre las células ováricas inhibiendo la acción de las gonadotrofinas y la síntesis de esteroides $(2,3)$. En una gran variedad de órganos, incluido el hígado y los riñones, el cortisol es oxidado a cortisona (metabolito inactivo) por la enzima $11 \beta$-hidroxiesteroide deshidrogenasa (11ßHSD) (4). A la fecha se han descrito 2 isoformas bioquímicamente distintas de la $11 \beta \mathrm{HSD}$, designadas $11 \beta H S D$ tipo 1 ( $11 \beta H S D-1)$ y $11 \beta H S D$ tipo 2 (11ßHSD-2) (5).

Se han determinado las bases moleculares de la transición de $11 \beta$ HSD-2 a $11 \beta$ HSD-1 durante la luteinización, concluyendo que la sobreexpresión de 11ßHSD-1 en el momento de la ovulación es inducida por las gonadotrofina (6). Como la ovulación es un evento inflamatorio, caracterizado por un incremento en la síntesis de interleuquinas y prostaglandinas (7), la generación incrementada de glucocorticoides antiinflamatorios por la actividad reductasa de la $11 \beta \mathrm{HSD}-1$ en el momento de la ovulación, podría representar un mecanismo fisiológico para limitar el proceso inflamatorio en el ovario $(8,9)$. En este sentido, se ha demostrado que los glucocorticoides inhiben la síntesis de prostaglandinas y citoquinas pro-inflamatorias en el ovario (10). Debido a que la expresión de $11 \beta \mathrm{HSD}$ es estimulada en las células de la granulosa por la LH y por citoquinas proinflamatorias (11), la síntesis de glucocorticoides vía $11 \beta H S D-1$ podría ser incrementada por las gonadotrofinas y/o citoquinas, como un aspecto integral de la cascada de la ovulación.

En trabajos realizados en bovinos, Tetsuka et al (12), describieron que las células granulosas bovinas en folículos antrales grandes, solamente expresan ARNm correspondiente a 11BHSD-1, mientras que no detectaron ARNm para $11 B H S D-$ 2. En el cuerpo lúteo bovino, se co-expresaron ambos isotipos, siendo predominantes el ARNm para $11 \beta \mathrm{HSD}-1$ en los cuerpos lúteos activos y el ARNm para $11 \beta$ HSD-2 en cuerpos lúteos en regresión (12). Datos informados recientemente sugieren que la expresión y actividad de $11 \beta H S D-$ 2 es predominante en las células granulosas en todos los estadios de desarrollo folicular activo bovino, con una transición a la isoforma $11 \beta \mathrm{HSD}-$ 1 en el cuerpo lúteo (13). Los únicos datos previos en quistes foliculares bovinos indicarían que existen moduladores de la acción de estas enzimas, no muy bien caracterizadas hasta el momento (5). 
Presumiblemente y teniendo en cuenta datos publicados por otros autores (5), las enzimas que participan en el metabolismo de glucocorticoides, particularmente el cortisol podrían participar en la patogenia de los quistes foliculares en el ovario de los bovinos. El cortisol es generado por un estimulo de la hormona adrenocorticotropa $(\mathrm{ACTH})$ a nivel adrenal pudiendo interferir con los mecanismos que regulan el cronograma de eventos dentro de la fase folicular. Esto ocurre principalmente a nivel del eje hipotálamohipofisiario-gonadal donde se reducen los pulsos de GnRH y LH por acciones tanto en la hipófisis como en el hipotálamo, privando al ovario de adecuados niveles de LH (14). Por esto es que el estrés ha sido propuesto como uno de los factores predisponentes más importantes (15), en el desarrollo de quistes foliculares en bovinos.

El objetivo de esta investigación fue identificar por inmunohistoquímica la expresión de las isoformas 1 y 2 de la enzima 11ß-hidroxiesteroide deshidrogenasa (11ßHSD) y su relación con el metabolismo de glucocorticoides en tejidos ováricos bovinos sanos y con Enfermedad Quística Ovárica (COD).

\section{MATERIALES Y MÉTODOS}

Obtención y procesamiento de muestras de frigorífico. Se recolectaron los ovarios de 20 bovinos Holando Argentino en frigoríficos de la zona (Esperanza, Provincia de Santa $\mathrm{Fe}$, Argentina). Muestras de 10 vacas con desarrollo folicular normal y 10 que presentaron alteraciones macroscópicas, compatibles con la existencia de COD (folículo mayor a $20 \mathrm{~mm}$, en ausencia de cuerpo lúteo y sin tono uterino) (1517). Los ovarios obtenidos se disecaron y fijaron en formol bufferado al $10 \%$ durante $6 \mathrm{~h}$ a $4^{\circ} \mathrm{C}$, luego se lavaron en buffer fosfato salino (PBS) y procesaron siguiendo protocolos de rutina para efectuar la inclusión en parafina (16).

Para hacer una caracterización inicial y evidenciar la morfología general se utilizó la coloración de hematoxilina-eosina.

Inmunohistoquímica. Se efectuaron cortes seriados, de $4 \mu \mathrm{m}$ de espesor, los que se montaron en portaobjetos previo tratamiento con 3-aminopropyl-triethoxysilane (Sigma, USA). Para la determinación de las enzimas $11 \beta$ HSD-1 y $11 \beta$ HSD-2 se realizó una técnica de inmunohistoquímica indirecta con la siguiente secuencia: primero se desparafinó, rehidrató y realizó recuperación antigénica a los cortes mediante calentamiento en microondas, luego se realizó bloqueo de la actividad de la peroxidasa endógena y de las uniones inespecíficas mediante el uso de sueros no inmunes y albúmina sérica bovina de acuerdo a lo descrito y validado previamente $(16,17)$. Los anticuerpos primarios para cada una de las enzimas (11ßHSD-1 1:100; Abcam, UK, Cat \# 39364 y 11ßHSD-2 1:800; Abcam, UK, Cat \# 37800) se incubaron $18 \mathrm{~h}$ a $4^{\circ} \mathrm{C}$. Posteriormente, las muestras se lavaron en PBS y se incubaron 40 minutos a $18^{\circ} \mathrm{C}$ con el anticuerpo biotinilado, según el anticuerpo primario utilizado; para el anticuerpo secundario $11 \beta \mathrm{HSD}-2$ se incubó además el anticuerpo puente anti IgY; luego se incubó el complejo estreptavidina-peroxidasa; después la reacción para cada enzima se reveló utilizando 3.3' diaminobencidina (DAB) como cromógeno; finalmente se hizo contracoloración con hematoxilina activada, se deshidrataron los cortes y se montaron con bálsamo de Canadá $(16,17)$. Los anticuerpos utilizados y sus respectivas concentraciones se encuentran detallados en el tabla 1.

Tabla 1. Anticuerpos primarios usados en la técnica de Inmunohistoquímica.

\begin{tabular}{lccc}
\hline \multicolumn{3}{c}{ Anticuerpos usados, proveedor y diluciones } \\
Anticuerpo & Tipo & Proveedor & Concentración \\
\hline Anti $11 \beta$ HSD-1 & Policlonal & Abcam & $1: 100$ \\
Anti $11 \beta$ HSD-2 & Policlonal & Abcam & $1: 800$ \\
Anti IgY & Policlonal & Abcam & $1: 600$ \\
\hline
\end{tabular}

Análisis de los resultados. Las imágenes microscópicas generadas con un microscopio Olympus $\mathrm{CH} 30$, se digitalizaron mediante una cámara SONY CCD-IRIS conectada a una PC de escritorio. Los resultados de inmunohistoquímica se evaluaron determinando la densidad óptica por análisis digital de imágenes, utilizando el sistema Image-Pro Plus 3.0.1 (Media Cybernetics). Para ello se realizó la segmentación automática de colores, de acuerdo a la intensidad de la reacción en los controles positivos, siguiendo las técnicas descriptas previamente $(16,17)$.

Los datos fueron evaluados con el programa SPSS 10.1 (SPSS Inc. USA) para Windows. Se realizó un análisis con pruebas paramétricas ANOVA y el post-test de Duncan para los diferentes grupos, de acuerdo a lo propuesto por Siegel (18) y Zar (19). Específicamente para cada isoforma se evaluó la inmunomarcación en las tres capas foliculares (granulosa, teca interna y teca externa) de folículos primarios, secundarios, terciarios y atrésicos en ovarios de animales sanos y folículos quísticos en animales con COD. 


\section{RESULTADOS}

Se demostró la presencia de las isoformas tipo I y II de $11 \beta H S D$ en tejidos ováricos bovinos obtenidos de frigorífico, mediante la aplicación de la técnica de inmunohistoquímica indirecta.

\section{Expresión de enzimas relacionadas con} el metabolismo de glucocorticoides en el ovario bovino. En las células que rodean el ovocito de los folículos primarios, se presentó una leve marcación positiva para la $11 \beta \mathrm{HSD}-1$ (Figura 1). En las células de la granulosa y de la teca externa de los folículos secundarios se observó también una débil marcación positiva (Figura 1). En las tres capas foliculares de los folículos terciarios y atrésicos se presentó marcación positiva para la $11 \beta \mathrm{HSD}-1$ (Figura 1 ). En las células de la granulosa de los folículos quísticos se observó una intensa marcación positiva (Figura 1).

En cuanto a la enzima $11 \beta$ HSD-2 se evaluó la inmunomarcación en las tres capas foliculares (Granulosa, Teca Interna y Teca Externa) de folículos primarios, secundarios, terciarios, atrésicos y quistes.
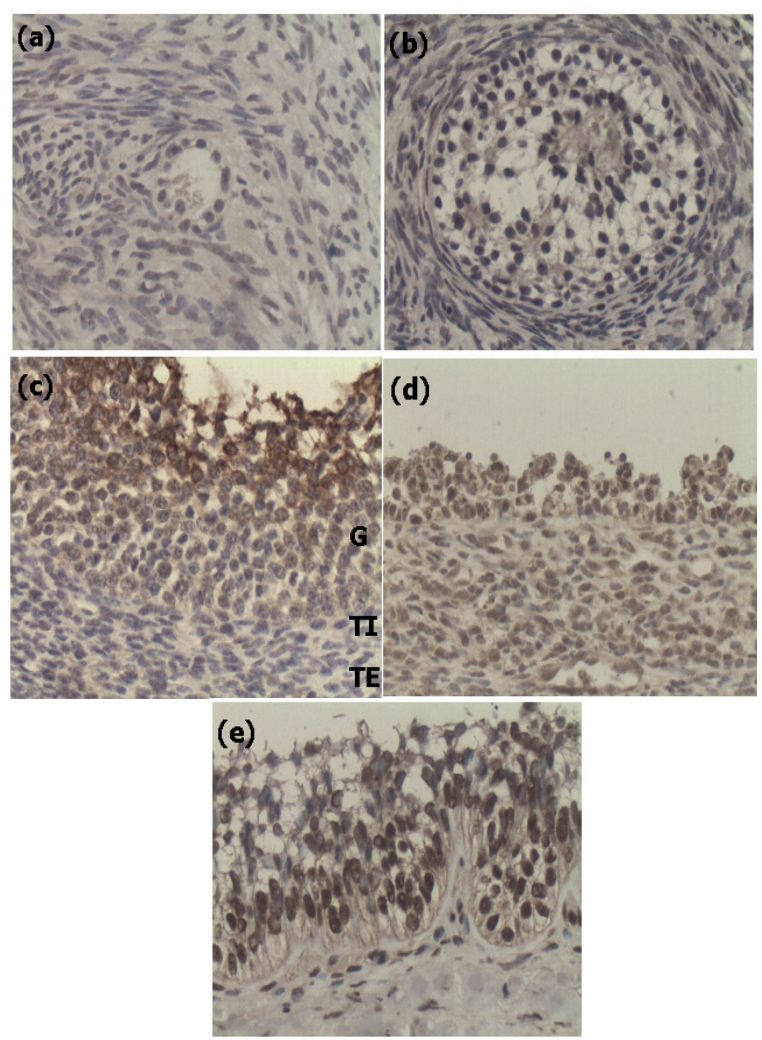

Figura 1. Pared de estructuras foliculares de ovario bovino inmunomarcadas para 11ßHSD-1. 40X. (a) Folículo Primario. (b) Folículo Secundario. (c) Folículo Terciario. (d) Folículo Atrésico (e) Folículo Quístico.
Se presentó marcación positiva para la enzima $11 \beta$ HSD- 2 en las células de la granulosa tanto de los folículos primarios como de los folículos secundarios, para las células de la teca externa de estos últimos también hubo marcación positiva (Figura 2). En los folículos terciarios, se observó una leve marcación positiva en las células de la granulosa, teca interna y teca externa (Figura 2). Asimismo se presentó una intensa marcación positiva en las células de la granulosa, teca interna y teca externa de los folículos atrésicos (Figura 2). En las células de la granulosa y teca interna de los folículos quísticos también hubo una intensa marcación de la enzima 11ßHSD-2 (Figura 2).

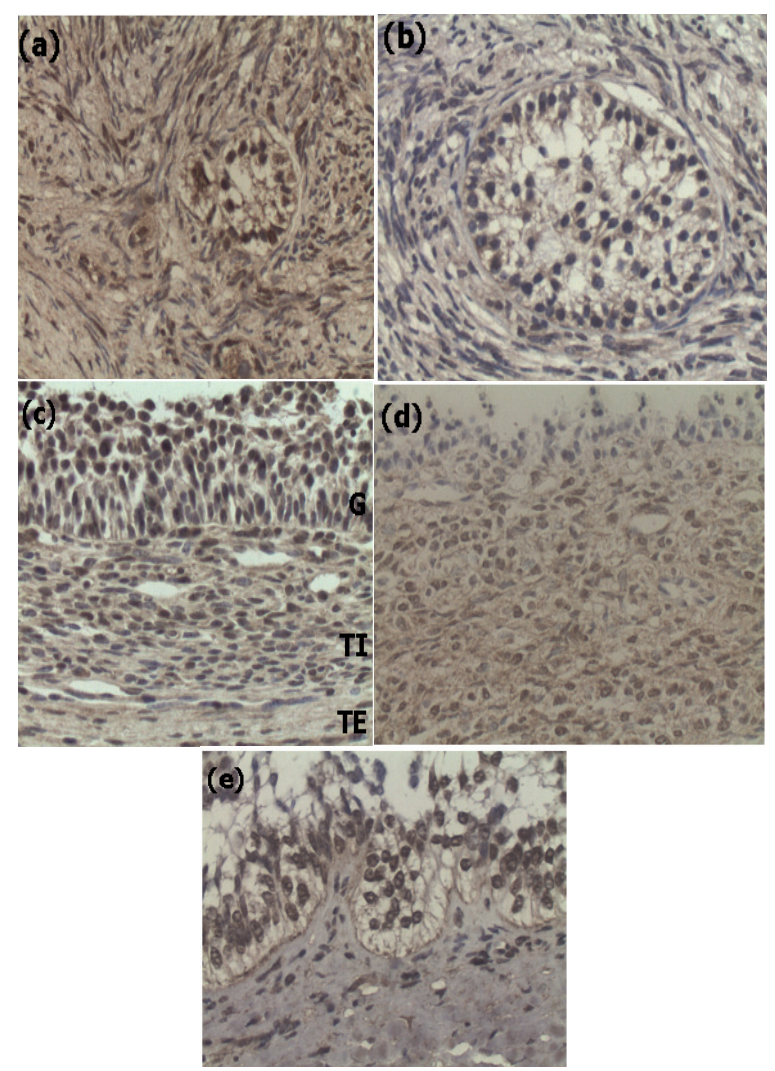

Figura 2. Pared de estructuras foliculares de ovario bovino inmunomarcadas para 11ßHSD-2. 40X. (a) Folículo Primario. (b) Folículo Secundario. (c) Folículo Terciario. (d) Folículo Atrésico (e) Folículo Quístico. G: granulosa; TI: teca interna; TE: teca externa.

Inmunohistoquímica $11 \beta$ HSD-1. La inmunomarcación positiva de la $11 \beta \mathrm{HSD}-$ 1 en la capa de la granulosa presentó diferencias significativas $(p<0.05)$ para folículos terciarios y folículos quísticos con relación a los folículos primarios y folículos secundarios, presentándose además un 
porcentaje intermedio de inmunomarcación para folículos atrésicos. El porcentaje del área inmunopositiva de la $11 \beta$ HSD-1, no mostró diferencias significativas en la teca interna de las diferentes estructuras foliculares (folículos terciarios, folículos atrésicos y folículos quísticos). No se halló diferencia en el porcentaje del área inmunopositiva de la enzima $11 \beta \mathrm{HSD}-1$ en la teca externa de los folículos secundarios, folículos terciarios, folículos atrésicos y folículos quísticos (Figura 3).

Inmunohistoquímica 11 BHSD-2. El porcentaje del área inmunopositiva de la $11 \beta$ HSD-2, en la capa de la granulosa, fue mayor para folículos atrésicos y folículos quísticos con relación a los folículos primarios, presentándose además valores intermedios
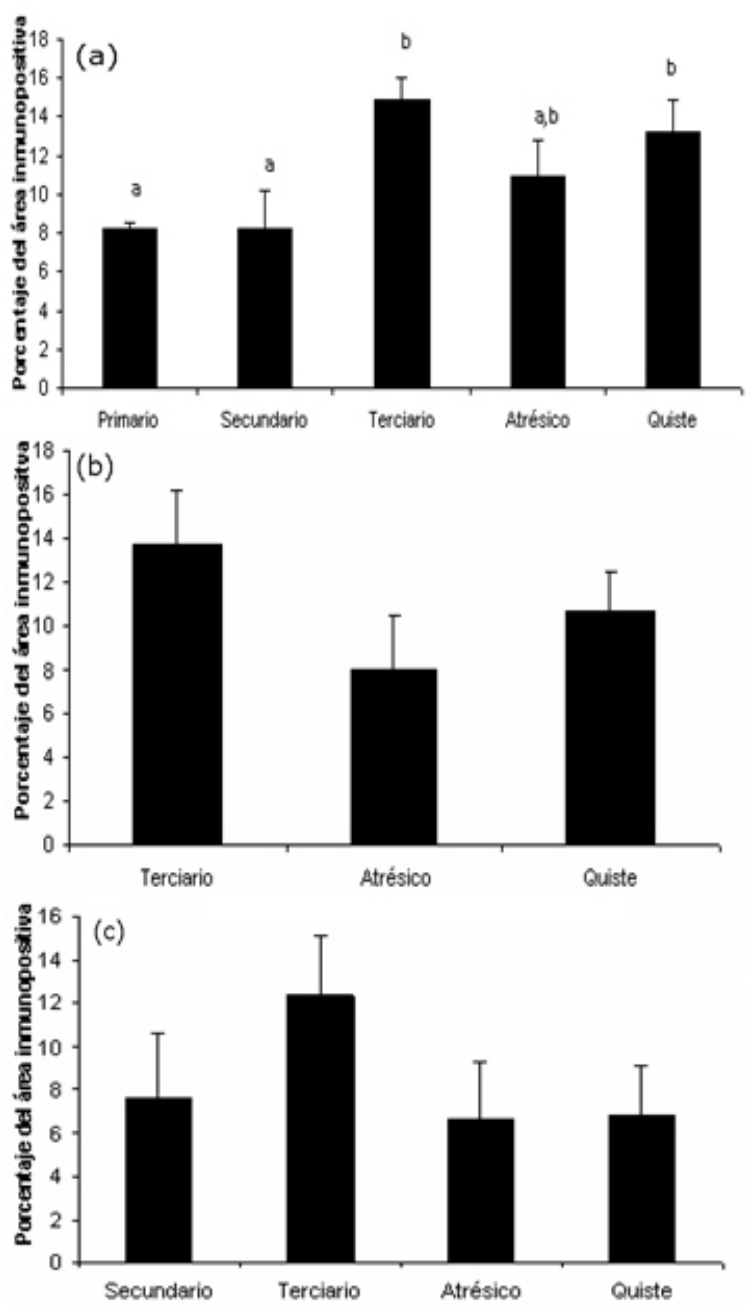

Figura 3. Porcentaje del área inmunopositiva para la enzima $11 \beta \mathrm{HSD}-1$ en las células de varios tipos foliculares en muestras obtenidas de frigorífico. (a) Granulosa. (b) Teca Interna. (c) Teca Externa. sin diferencias significativas para folículos secundarios y folículos terciarios. En las células de la Teca Interna, el porcentaje del área inmunopositiva para $11 \beta \mathrm{HSD}-2$ evidenció una diferencia significativa para folículos atrésicos y folículos quísticos con relación a los folículos terciarios. La inmunomarcación de la enzima $11 \beta$ HSD-2, en las células de la Teca Externa, fue mayor para folículos atrésicos con relación a folículos terciarios, asimismo el porcentaje para folículos secundarios y folículos quísticos tuvieron valores intermedios sin diferencias significativas (Figura 4).
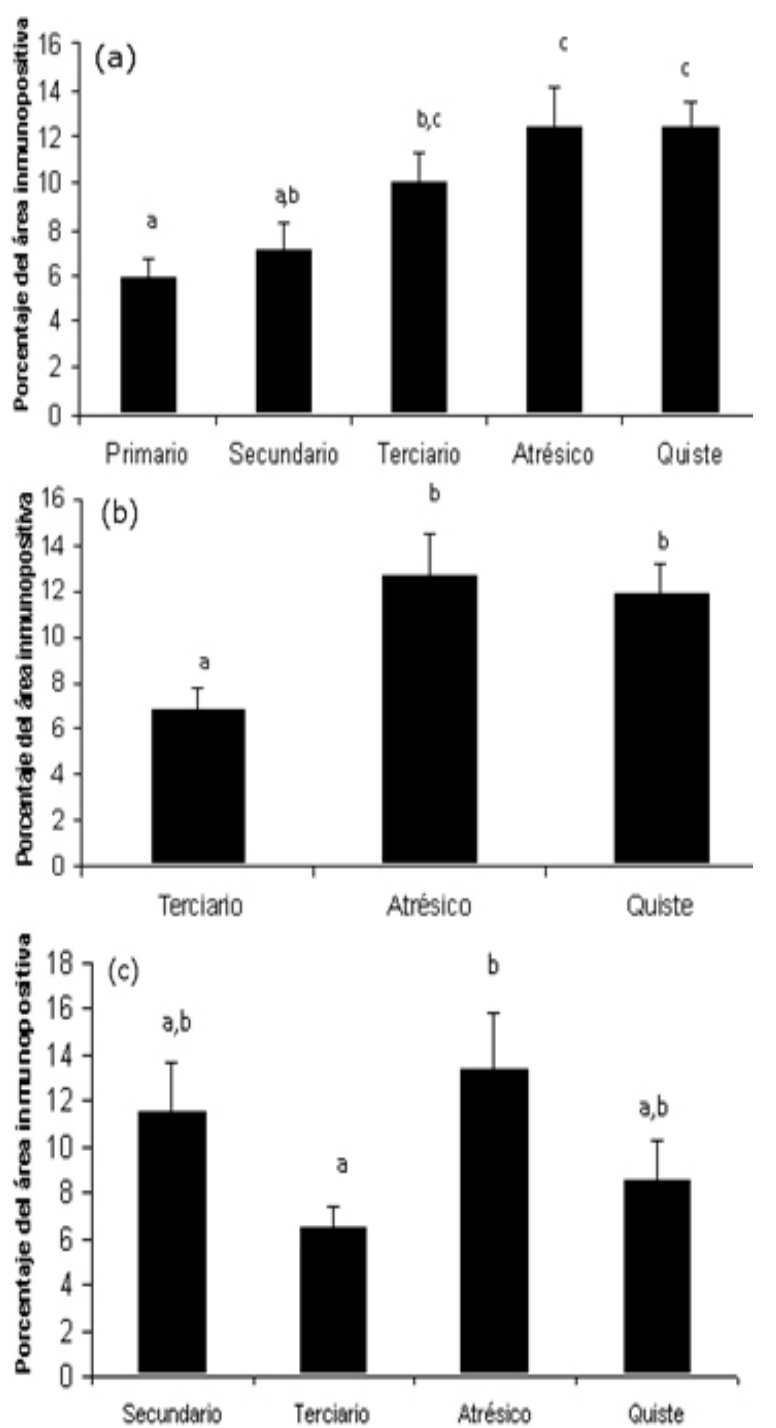

Figura 4. Porcentaje del área inmunopositiva para la enzima $11 \beta \mathrm{HSD}-2$ en las células de varios tipos foliculares en muestras obtenidas de frigorífico. (a) Granulosa. (b) Teca Interna. (c) Teca Externa. 


\section{DISCUSIÓN}

Los quistes foliculares son uno de los desordenes reproductivos mas comunes en vacas lecheras, presentándose también en animales destinados a la producción de carne. Se ha descrito que en diferentes tipos de rodeos, pueden afectar hasta un $15 \%$ de las vacas durante el periodo postparto, prolongando el intervalo parto-concepción (20) y causando perdidas significativas a la producción pecuaria. Además, los quistes, a veces, son acompañados por la expresión de conducta sexual receptiva (estro), resultando en costos adicionales por las infructuosas inseminaciones artificiales (21).

Watson y Cliff (22) detectaron diferentes incidencias de quistes foliculares durante la investigación de anestro (58\%), celos irregulares $(12 \%)$, diagnósticos negativos de preñez (12\%), y exámenes pre-servicio (17\%). Dentro de sus causas, el estrés ha sido propuesto como uno de los factores predisponentes más importantes (15).

Los estresores reducen la fertilidad por interferir con los mecanismos que regulan el cronograma de eventos dentro de la fase folicular. Esto ocurre principalmente a nivel del eje hipotálamohipofisiario-gonadal donde se reducen los pulsos de GnRH y LH por acciones tanto en la hipófisis como en el hipotálamo, privando al ovario de adecuados niveles de LH (14).

En este trabajo, se corroboró la expresión de enzimas vinculadas con el metabolismo de los glucocorticoides (5), más específicamente las isoformas de la enzima $11 B H S D$, en folículos ováricos bovinos, inclusive hasta estadios patológicos de los mismos. Se hallaron diferencias significativas, para la enzima $113 \mathrm{HSD}-1$, en el porcentaje del área inmunopositiva en las células de la granulosa del folículo terciario y folículo quístico con relación a folículo primario y folículo secundario, asimismo el folículo atrésico tuvo una expresión intermedia con relación a los folículos evaluados; para esta misma enzima, no se hallaron diferencias significativas en el porcentaje del área inmunopositiva para las células de la teca interna y la teca externa respectivamente.

Se evidenciaron diferencias significativas en la inmunomarcación con la 11BHSD-2 en la capa de la granulosa, en particular al comparar el folículo primario con el folículo atrésico y quístico; también, pero en las células de la teca externa, se presentaron diferencias significativas en el porcentaje del área inmunopositiva entre folículo terciario en relación con folículo atrésico y folículo quístico. Fueron importantes también las diferencias en la inmunomarcación de la enzima 11 BHSD- 2 en las células de la teca externa, puesto que los valores mínimos y máximos de expresión se hallaron en folículo terciario y folículo quístico respectivamente, en comparación con los valores intermedios para folículo secundario y folículo quístico.

Con estos resultados se puede sugerir que las isoformas de la enzima 11 BHSD se encuentran en actividad en los diferentes estadios de desarrollo folicular, siendo evidente la síntesis de la enzima 11BHSD-1 en folículos de ovario bovino presentes en la ovulación, y por consiguiente la activación local de cortisol, el cual a nivel ovárico puede cumplir funciones de regulación mediante mecanismos paracrinos. A pesar de la poca información científica con relación a la presencia de receptores de ACTH a nivel ovárico en bovinos, son sólidas las evidencias de la participación del cortisol en la regulación del proceso ovulatorio (26), y la expresión de enzimas relacionadas a su activación/inactivación pueden representar uno de los mecanismos mediante el cual se altere el patrón normal de desarrollo folicular, y por consiguiente la generación de quistes foliculares.

Basados en estos resultados se puede sugerir que la regulación del metabolismo del cortisol en el ovario podría jugar un papel clave en la patogenia de algunas enfermedades relacionadas con anestro debido al estrés. Por ejemplo, la ACTH estimula la liberación de cortisol y progesterona, en respuesta a situaciones de estrés. Por su parte la progesterona actúa inhibiendo la liberación de GnRH en el hipotálamo, mientras que el cortisol ejerce un efecto inhibitorio directo en el ovario sobre la secreción de estradiol y sobre el contenido de receptores de $\mathrm{LH}$. Consecuentemente falla el mecanismo de retroalimentación positiva de los estrógenos, suprimiendo el pico preovulatorio de $\mathrm{LH}$, bloqueando la ovulación y generando el desarrollo de quistes foliculares $(23,24)$.

En trabajos previos se observó una respuesta diferencial de los quistes en relación a los folículos terciarios en la secreción de cortisol y estradiol frente a un estimulo con ACTH. Estos resultados indican que la ACTH puede afectar la secreción de esteroides en los folículos de ovarios bovinos y que los quistes foliculares tienen una respuesta diferencial, en relación a los folículos normales (25). Estos hallazgos apoyan la idea de que el estrés afecta la función ovárica y que esto puede ser un importante factor etiológico de los quistes foliculares en bovinos.

Los resultados del análisis inmunohistoquímico en tejidos ováricos bovinos de este estudio, permiten inferir la existencia de un mecanismo endocrino 
soportado en activaciones e inactivaciones hormonales subsecuentes regidas por factores generales y específicos inherentes al bovino, que originan el cuadro característico de quistes foliculares espontáneos, del cual se debe partir para dilucidar la patogenia de esta disrupción reproductiva al trabajar con quistes foliculares inducidos y al aplicar técnicas celulares y moleculares de mayor especificidad.
Asimismo se concluye que aunque se ha descripto que los folículos ováricos de bovino presentan la capacidad de liberar cortisol en respuesta a estímulos mediados por gonadotropinas, esta capacidad se encuentra aumentada en los quistes foliculares. Esto podría indicar una capacidad de regulación de los niveles locales de glucocorticoides independientemente de los niveles sistémicos, coincidiendo con lo propuesto por otros autores (2).

\section{REFERENCIAS}

1. Greco D, Stabenfeldt GH. Las glándulas endocrinas y su función. En: Cunningham, JG. Fisiología Veterinaria. Tercera edición. Madrid: Ed. Elsevier; 2003.

2. Acosta TJ, Tetsuka M, Matsui M, Shimizu T, Berisha B, Schams D et al. In Vivo Evidence that Local Cortisol Production Increases in the Preovulatory Follicle of the Cow. J Reprod Dev 2005; 51:483-489.

3. Sunak N, Green DF, Abeydeera LR, Thurston $L M$, Michael AE. Implication of cortisol and $11 \beta$-hydroxyesteroid dehydrogenase enzymes in the development of porcine (Sus scrofa domestica) ovarian follicles and cysts. Reproduction 2007; 133:1149-1158.

4. Kotelevstev Y, Seckl JR, Mullins JJ. $11 \beta$-Hydroxysteroid dehydrogenases: key modulators of glucocorticoid action in vivo. Curr Opin Endocr Diabet 1999; 6:191-198.

5. Thurston LM, Jonas KC, Abayasekara DRE, Michael AE. Ovarian Modulators of $11 \beta$-Hydroxyesteroid Dehydrogenase $(11 \beta H S D)$ activity in Follicular Fluid from Bovine and Porcine Large Antral Follicles and Spontaneous Ovarian Cysts. Biol Reprod 2003; 68:2157-2163.

6. Michael A, Thurston LM, Rae MT. Glucocorticoid metabolism and reproduction: a tale of two enzymes. Reproduction 2003; 126:425-441.

7. Ando M, Kol S, Kokia E, Ruutiainen-Altman K, Sirois J, Rohan RM et al. Rat ovarian prostaglandin endoperoxide synthase-1 and -2: periovulatory expression of granulosa cell-based interleukin-1 dependent enzymes. Endocrinology 1998; 139:2501-2508.
8. Hillier SG, Tetsuka M. An anti-inflammatory role for glucocorticoids in the ovaries. J Reprod Immunol 1998; 39: 21-27.

9. Andersen CY. Possible new mechanism of cortisol action in female reproductive organs: physiological implications of the free hormone hypothesis. J Endocrinol 2002; 173: 211-217.

10. Telleria CM, Ou J, Sugino N, Ferguson $S$, Gibori G. The expression of interleukin- 6 in the pregnant rat corpus luteum and its regulation by progesterone and glucocorticoid. Endocrinology 1998; 139: 3597-3605.

11. Evagelatou $M$, Peterson $S L$, Cooke BA. Leukocytes modulate $11 \beta$-hydroxyesteroid dehydrogenase (11ßHSD) activity in human granulosa lutein cell cultures. Mol Cell Endocrinol 1997; 133: 81-88.

12. Tetsuka $M$, Yamamoto $S$, Hayashida $N$, Hayashi KG, Hayashi M, Acosta TJ et al. Expression of $11 \beta$-hydroxyesteroid dehydrogenases in bovine follicle and corpus luteum. J Endocrinol 2003; 177: 445-452.

13. Thurston LM, Abayasekara DRE, Michael AE. 11 $\beta$-Hydroxyesteroid dehydorgenase expression and activities in bovine granulosa cells and corpora lutea implicate corticosterois in bovine ovarian physiology. J Endocrinol 2007; 193: 299-310.

14. Jordan ER. Effects of Heat Stress on Reproduction. J Diary Sci 2003; 86: (E. Suppl) 104-114. 
15. Vanholder T, Opsomer G, de Kruif A. Aetiology and pathogenesis of cystic ovarian follicles in dairy cattle: a review. Reprod Nutr Dev 2006; 46: 105-119.

16. Salvetti NR, Gimeno EJ, Lorente JA, Ortega $\mathrm{HH}$. Expression of cytoskeletal proteins in the follicular wall of induced ovarian cysts. Cells Tissues Organs 2004; 178: 117-125.

17. Ortega $H H$, Stangaferro $M L$, Salvetti NR, Arcangelo D. Estudio del balance proliferación/apoptosis en estructuras foliculares de bovinos con enfermedad quística ovárica inducida experimentalmente. Medicina 67 2007; (Supl. III): 186.

18. Siegel S. Nonparametric statistics for the behavioral sciences. New York: Ed. McGrawHill; 1956.

19. Zar JH. Biostatistical analysis. New Jersey: Prentice-Hall International Editions; 1984.

20. Silvia WJ, McGinnis AS, Hatler TB. A comparison of adrenal gland function in lactating dairy cows with or without ovarian follicular cysts. Biol Reprod 2005; 5: 19-29.

21. Webb R, Gutierrez CG, Gong JG, Campbell BK. Dynamics and aetiology of ovarian follicular cysts in post-partum dairy cattle. Reprod Domest Anim 1998; 33: 285-288.
22. Watson CL, Cliff AJ. A survey of cystic ovarian disease in practice. Bov Pract 1997; 31: 15-18.

23. Kawate $N$, Akiyama $M$, Suga $T$, Inaba $T$, Tamada $H$, Sawada $T$ et al. Change in concentrations of luteinizing hormone subunit messenger ribonucleic acids in the estrous cycle of beef cattle. Anim Reprod Sci 2001; 68: 13-21.

24. Kawate N, Inaba T, Mori J. Effects of cortisol on the amounts of estradiol- $17 \beta$ and progesterone secreted and the number of luteinizing hormone receptors in cultured bovine granulosa cells. Anim Reprod Sci 1993; 32: 15-25.

25. Ortega $\mathrm{HH}$, Amweg A, Paredes A, Salvetti $\mathrm{N}$, Lara $\mathrm{H}$. ACTH induces differencial changes in steroidal hormone secretion in the wall of bovine antral and cystic follicles. Biol Reprod 2009; 81: 528.

26. Amweg. Ayelen, (2009). Análisis de la expresión de las isoformas tipo I y II de 11 $\beta$-Hidroxihesteroide Deshidrogenasa en las distintas estructuras ováricas bovinas con Enfermedad Quística Bovina. Tesina de Grado para Obtener el Título de Licenciada en Biotecnología de la Facultad de Bioquímica y Ciencias Biológicas - UNL 